\title{
Alt ekstremite alçıları ve endikasyonları
}

\section{Lower extremity casting and indications}

\author{
Cem Çopuroğlu, Murat Erem \\ Trakya Üniversitesi Tıp Fakültesi, Ortopedi ve Travmatoloji Anabilim Dalı, Edirne
}

\begin{abstract}
Travma veya inflamasyon nedeniyle oluşan kas ve iskelet sistemi patolojilerini kontrol altına almak, ekstremiteleri veya eklemleri immobilize etmek ve korumak için alçı ve ateller kullanılır. Sirküler alçı, alt ekstremitenin çepeçevre sarılarak immobilize edilmesi için uygulanan tespit yöntemidir. Alt ekstremite yaralanmalarında sıklıkla uzun bacak ve kısa bacak alçılar kullanılmakla birlikte, patellar tendon bearing (PTB) alçısı, total temas alçısı ve pelvipedal alçı gibi daha spesifik endikasyonları olan alçılar da kullanılmaktadır. Alçı ve atel uygulaması yapılmadan önce, karşılaşılabilecek riskler hastaya mutlaka anlatılmalı ve hasta onamı alınmalıdır. İyi uygulanmadığı durumlarda basınç yaraları, kompartman sendromu ve alçı sendromu gibi komplikasyonlar akılda tutulmalıdır. Bu nedenle, her ortopedist alçı ve atel uygulamalarını usulüne uygun olarak yapabilecek yeterliliğe sahip olmalıdır. Önlüğünde veya formasında alçı lekesi olmayan ortopedist olmaz ve her ortopedist için alçı yapmak sanattır.
\end{abstract}

Anahtar sözcülkler: alt ekstremite, alçı; tam temas alçısı; pelvipedal alçı; total temas alçısı

T ravma veya inflamasyon nedeniyle oluşan kas ve iskelet sistemi patolojilerini kontrol altına almak, ekstremiteleri veya eklemleri immobilize etmek ve korumak için alçı ve ateller kullanılır. ${ }^{[1,2]}$

Bilinen en eski ekstremite atelleri, M. Ö. 3000-2500 yılları arasında Mısır'da mumyalarda rastlanan atellerdir. Bu ateller, ağaç lifleri ve sopalarla yapılmıştır. Hipokrat (M. Ö. 460-377) kırık bakımı için atel ve 'silindir' bandajın önemli olduğunu belirtse de, atellerde sıva malzemelerinden bahsetmemiştir. Daha sonraki dönemlerde atellere mum, zift, domuz yağı veya reçine eklenmeye başlanmıştır. Modern anlamda ilk kullanımı İbni Sina (980-136) tarafından tanımlanmış olup, alçı içeriği deniz kabuklarındaki kireç ve yumurta akından oluşan karışımdır. ${ }^{[3,4]}$

Atel veya splintler, ekstremiteyi uzunlamasına bir ya da birkaç yüzeyden immobilize etmek için tasarlanmış materyallerdir. Sirküler alçı ise ekstremitenin çepeçevre
Casting is used to control the musculoskeletal system pathologies caused by trauma and inflammation, to immobilize and protect the extremity. Plaster of Paris cast is a useful circumferential stabilization method for lower extremity. Generally long leg cast and short leg cast is applied in lower extremity injury but also in some specific conditions patellar tendon bearing cast, total contact cast and hip spica cast can also be used. Complications and risks must be explained to patients before casting, and patients consent must be taken. If cast is not applied properly, pressure ulcers, compartment syndrome, cast syndrome may occur. Because of these complications every orthopedist should know how to apply casting with a proper technique. A doctor can not be an orthopedist without a plaster spotted uniform. Casting is an art for each orthopedist.

Key words: lower extremity; plaster of Paris; total contact cast; hip spica cast

sarılarak immobilize edilmesi için uygulanan tespit yöntemidir. Alçı ve atel uygulaması yapılmadan önce, karşılaşılabilecek riskler hastaya mutlaka anlatılmalı ve hasta onamı alınmalıdır. ${ }^{[1]}$

Günümüzde, pamuklu beze emdirilmiş kalsiyum sülfat hemihidrat moleküllerinden oluşan ve su ile ıslatılınca kısa süre sonra kuruyarak sertleşen alçılı sargılar (plaster of Paris bandage) ve fiberglas ya da poliüretan reçineden imal edilen sargılar yaygın olarak kullanılmaktadır. ${ }^{[5,6]}$ Farklı markaların farklı boyutlarda ürettiği alçılı sargılar ve fiberglas alçılar mevcut olup, fiberglas alçılar kapalı paket içinde piyasada bulunmaktadır. ${ }^{[6]}$

Mükemmel alçılama materyali, ekstremiteyi istenilen koşullar altında tam bir konforla muhafaza etmelidir. Güçlü ve hafif olmanın yanı sıra, gerekli olmadığında kolayca çıkarılabilmelidir. ${ }^{[5]}$ Her iki tip alçı malzemesinin birbirine göre avantaj ve dezavantajları bulunmakta olup, eldeki olanaklar, hasta tercihi ve tıbbi gereklilikler

- Illetişim adresi: Prof. Dr. Cem Çopuroğlu, Trakya Üniversitesi, Tıp Fakültesi Ortopedi ve Travmatoloji Anabilim Dalı, Edirne Tel: 0532 - 3361923 e-posta: cemcopur@hotmail.com

- Geliş tarihi: 1 Ağustos 2018 Kabul tarihi: 1 Ağustos 2018 


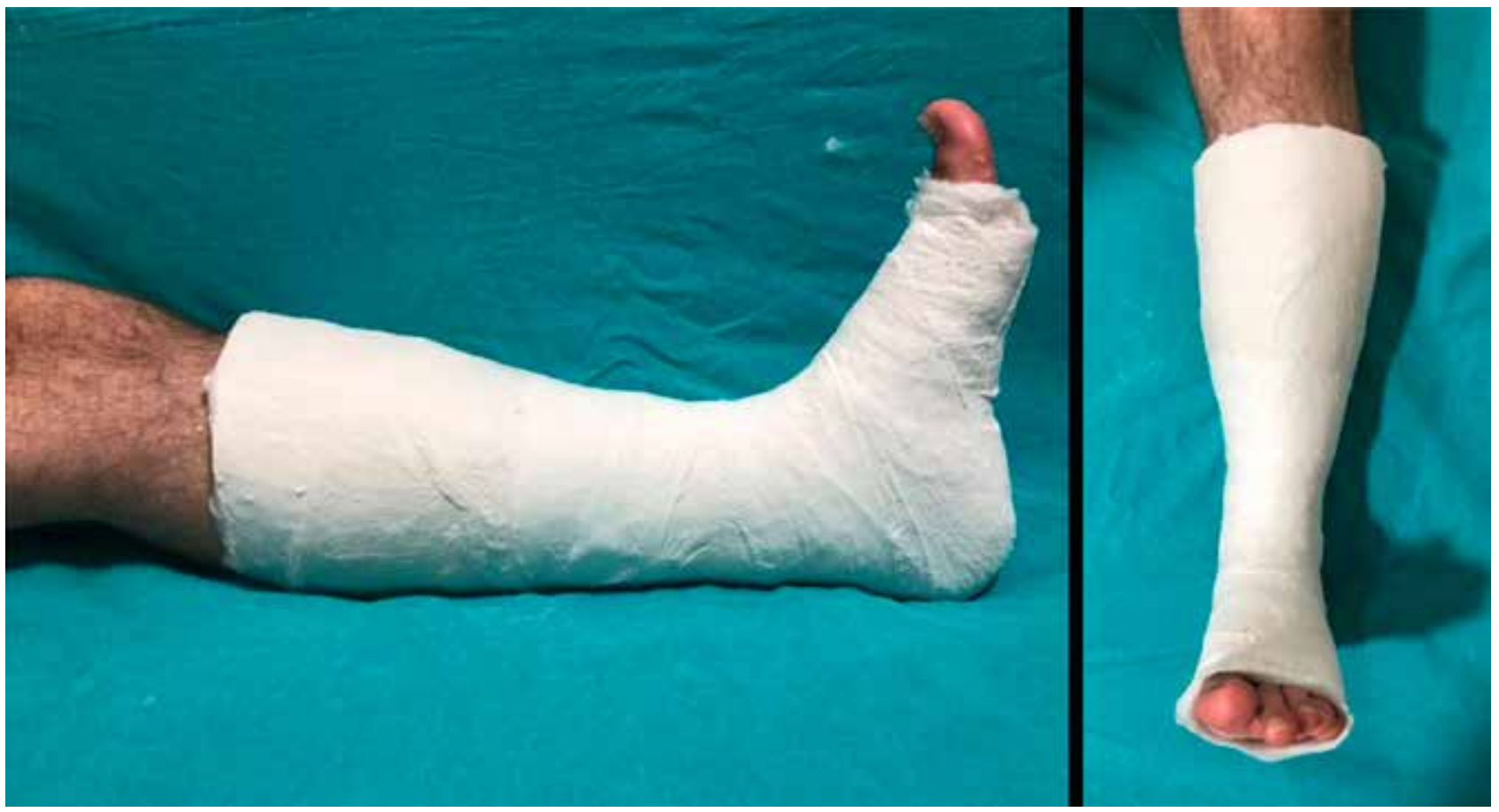

Şekil 1. Kısa bacak alçı.

göz önünde bulundurularak, uygun olan alçı malzemesi doktor tarafindan tercih edilebilir.

Ayrıca, alçının cilde direkt temas etmemesi için, alçı yapımında alçı altı pamuğu veya alçı çorabı (sitokinet) kullanılır. Bu yardımcı malzemeler, alçı çıkartımı sırasında da alçı motorunun cilde direkt temasına engel olarak koruyucu görevi görmektedir. ${ }^{[7,8]}$

$\mathrm{Bu}$ derlemenin amacı, alt ekstremiteye uygulanan alçı tiplerini ve endikasyonlarını özetlemektir. Alt ekstremitede kullanılan alçıları dizaltı ve dizüstü kullanım yerlerine göre gruplamak mümkündür.

\section{DiZALTI BÖLGEYE UYGULANAN ALÇILAR}

\section{Ayak Başparmak Alçısı}

Ayak 1. parmağını içine alıp sirküler şekilde destekleyen alçıdır. Uygulama pozisyonu başparmağın nötral pozisyonudur. Alçının ayaktan çıkmaması ve uygulandığı pozisyonu koruyabilmesi için, alçı metatarslar üzerinden sirküler şekilde sarılarak bir kemer yapılır. Uygulanacak alçının eninin $5 \mathrm{~cm}$ 'den fazla olmaması uygulamayı zorlaştırır. Metatarsofalangeal eklem seviyesinden geçerken pamuk ve alçı " 8 " yapacak şekilde sarılmalıdır. Alçının 1. web aralığında bası yarasına neden olmaması için dikkatli olunmalıdır. ${ }^{[2,6]}$

\section{Endikasyonlar $^{[6]}$}

a) Ayak 1. parmak metatarsofalangeal ve interfalangeal eklem yaralanmaları

b) Birinci parmak proksimal ve distal falanks kırıklarında

c) Halluks valgus

d) Halluks rigidus

\section{Kısa Bacak Alçı (Şekil 1)}

Ayak bileği $90^{\circ}$ dorsifleksiyonda iken, ayak metatarsofalangeal eklemden parmakları dahil etmeden popliteal fossaya kadar uzatılabilen alçıdır. ${ }^{[1]}$ Ayak bileği rotasyonunu ayarlayabilmek için, 2. ve 3. parmaklar dizkapağı ile aynı hizada olmalıdır. Ayak bileği anteriorunda sitokinet katlantı oluşturmamalıdır. Bu duruma engel olmak için, sitokinet kesilerek bası yarası oluşması engellenebilir. Aşil yaralanmaları ya da kalkaneus dil kırıklarında ayak bileği dorsifleksiyonu verilmez. Alçı proksimalini fibula başından $5 \mathrm{~cm}$ distalde bitirmek gereklidir. Bu tedbir, fibular sinir arazı ve düşük ayak komplikasyonuna engel olabilmek için gereklidir. Hastanın ayağını sedye kenarından ya da sandalyeden sarkıtır pozisyonda alçıyı uygulamak, kırık redüksiyonuna yardımcı olacaktır. ${ }^{[2,6]}$ 


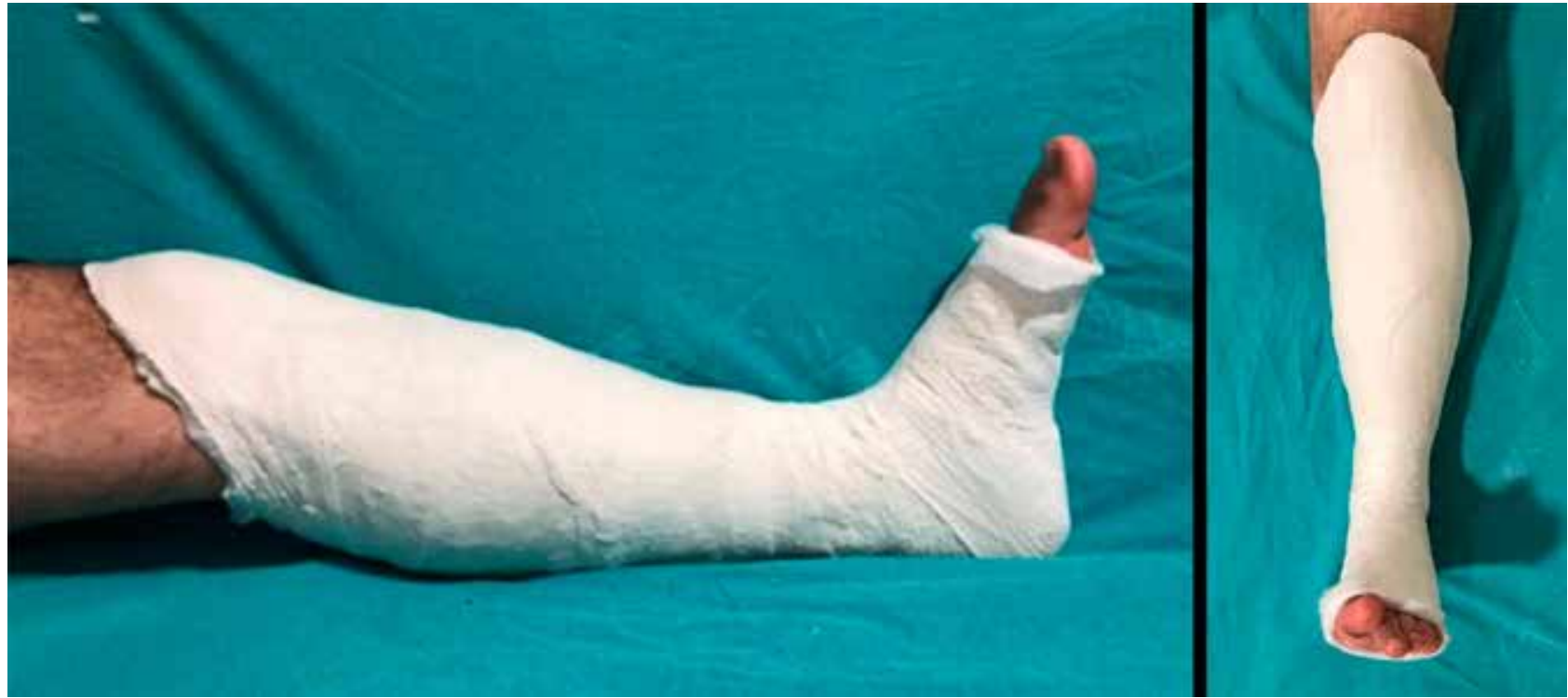

Şekil 2. Patellar tendon bearing (PTB) alçıSı.

\section{Endikasyonlar ${ }^{[6,9,10,11]}$}

a) Ayak, ayak bileği ve kruris yumuşak doku yaralanmalarında

b) Metatars kırıklarında

c) Ayak bileği mediyal, lateral ve posterior malleol kırıklarında

d) Distal tibia ve fibula kırıklarında

e) Aşil tendon yaralanmalarında

f) Kalkaneus ve tarsal kemik kırıklarında

\section{Patellar Tendon Bearing (PTB) Alçısı (Şekil 2)}

ilk defa 1963 yılında Sarmiento tarafindan, tibia kırıklarının diz altı fonksiyonel yürüme alçısı ile tedavi yöntemi ortaya atılmıştır. ${ }^{[12]}$ PTB alçısı, kısa bacak alçıya benzer şekilde uygulanan bir alçıdır. Hasta, bacağını yukarıdan serbest bırakabilecek yükseklikte bir sandalyeye ya da sedyeye oturtularak uygulanır. Ayak bileğine $90^{\circ}$ dorsifleksiyonda uygulanan sirküler alçı, diz çevresine kadar kısa bacak alçıyla aynı şekilde uygulanır. Kısa bacak alçıdan farklı olan kısmı; alçının proksimal bölgesinde, posteriorda popliteal fossada diz fleksiyonunu engellemeyecek seviyeye kadar, anteriorda ise patellar oluklar desteklenecek şekilde patella ortasına kadar sirküler alçı uygulanmasıdır. Alçının proksimal kısmı uygulanırken dize $40^{\circ}$ fleksiyon verilir. Bu durumda, kuadriseps femoris kası tamamen gevşek durumda tutulmuş olur. Aksi takdirde alçı donduktan sonra diz tam ekstansiyona getirilemez. ${ }^{[12,13]}$ PTB, patella ve tibia proksimaline iyice oturması sayesinde rotasyonel stabilite de sağlar. ${ }^{[12]}$

Yük vermeye izin veren bu alçı tekniğinde, topukluk aparatı eklenerek yük verme kolaylaştırılır. ${ }^{[1,6]}$ Yapılan bir çalışmada, PTB'nin arka ayakta plantar basıncı azalttığı, ön ayakta plantar basınç artışına neden olduğu rapor edilmiştir. ${ }^{[14]}$

\section{Endikasyonlar [1,12,13]}

Tibianın cisim kırıklarının tedavisinde, uzun bacak alçısından sonra yeterli kaynama olmadığında ya da erken diz hareketi ve mobilizasyon hedeflendiğinde uygulanabilir.

\section{Total Temas Alçısı (Kontakt Alçısı)}

1930'lu yılların başından beri Hansen hastalığına yönelik olarak uygulanarak ve zaman içerisinde hissiz ayaklarda kullanılarak başarı sağlanmıştır. 2000'li yıllara doğru ise diyabetik nöropatiye bağlı geliş̧en kronik ayak tabanı ülserlerinin tedavisinde etkin bir şekilde kullanılmaya başlanmıştır. ${ }^{[15,16]}$

Hastanın tercihen yüzükoyun yatması alçı uygulamasını kolaylaştııır. Alçının genel yapım aşamaları diz altı alçı ile benzerlik göstermektedir. Proksimalde tuberositas tibianın 1-2 cm distaline kadar uzanan alçı, distalde ayak parmaklarından başlar. Bu alçı uygulanırken, alçı komplikasyonları açısından daha 


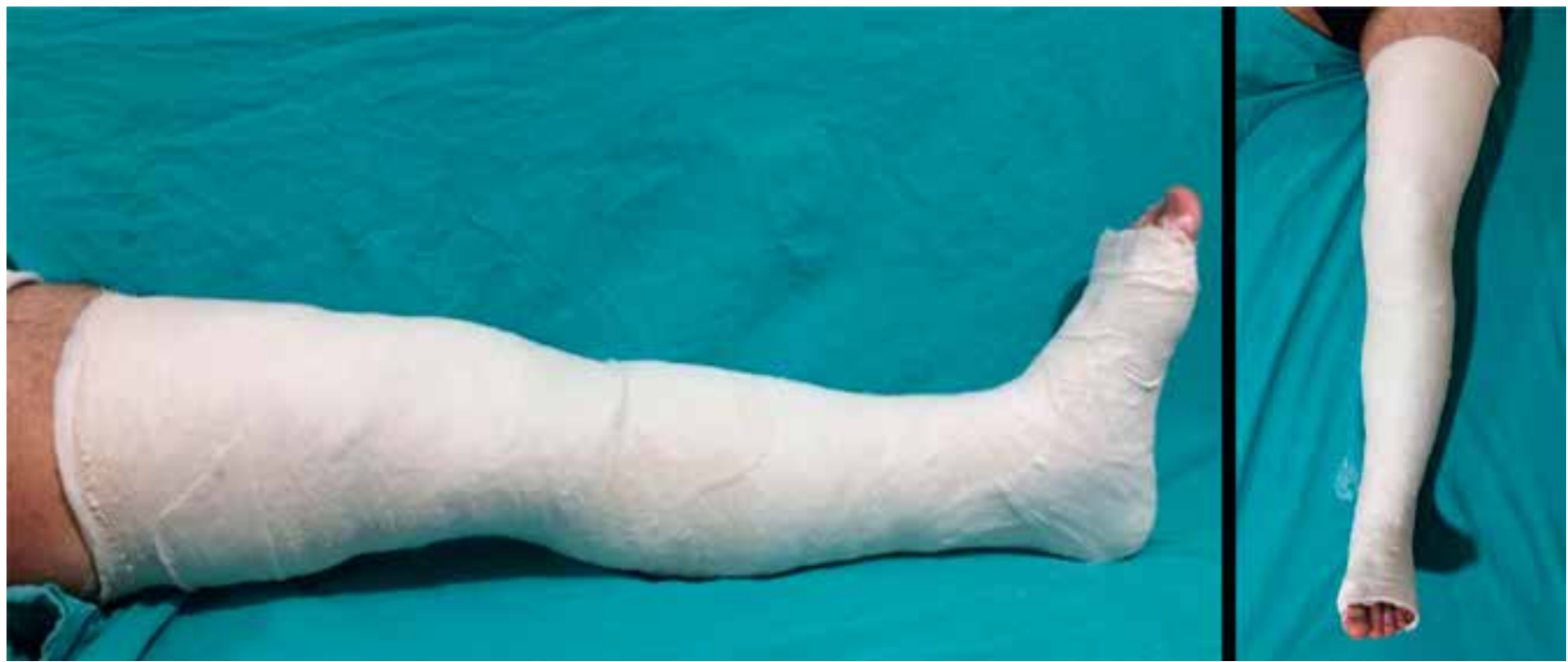

Şekil 3. Uzun bacak alçı.

dikkatli olunması gerekmektedir. Bu nedenle, alçı altı çorabı parmakları da örtecek şekilde iki kat olarak giydirilir. Mümkün olduğunca az pamuk kullanılır ve alçı içine yabancı cisim girmemesi için alçı uçları kapatılır. Malleollerin üzeri ekstra koruyucu malzemeler ile örtülür. Ayak bileği nötral pozisyonda yapılan alçıya, ayak ve bacağın şeklini tam alabilmesi için iyi şekil verilmelidir. Bu, alçıyı uygulayan hekimin tecrübe ve maharetiyle doğrudan ilgilidir. Alçının bozulmadan sertleşmesi için ilk 24 saat yük verilmemelidir. Sonrasında, hastaya yük vermesi ve günlük aktivitelerini yapması bilgisi verilir. Alçı genellikle 1. haftada değiştirilir. Bu alçının uygulandığı hastalar yakından takip edilmeli ve sorun tespit edildiğinde alçı değişimi yapılmalıdır. Yerinde bası yaraları oluşmaması ve alçının fonksiyonunun bozulmaması için kapak açma gibi girişimlerden uzak durulmalıdır. ${ }^{[15,17]}$

\section{Endikasyonlar ${ }^{[15-17]}$}

a) Diyabetik ayak

b) Ayak ön kısmındaki plantar bası yaraları

c) Erken evre Charcot hastalığı

\section{DIZÜSTÜ UYGULANAN ALÇILAR}

\section{Uzun Bacak Alçı (Şekil 3)}

Ayak, ayak bileği, kruris, diz ve uyluğunu sirküler şekilde saran alçıdır. Kısa bacak atel uygulama prensiplerine ek olarak, diz $15-20^{\circ}$ kadar hafif fleksiyona alınarak kasık bölgesine kadar uygulamaya devam edilir. ${ }^{[1]}$ Nörolojik komplikasyonlardan kaçınmak için, fibula başı hizasına ped ile destek yapılmalıdır. Bu bölgede bası olması, düşük ayak gelişmesine neden olabilir. Alçının proksimali uyluk arka bölgesinde bası yarasına neden olmaması için ped ya da pamukla desteklenmelidir. Uygulamanın yapılabilmesi için yardımcı sağlık personeline ihtiyaç vardır. ${ }^{[2,6]}$

\section{Endikasyonlar ${ }^{[1,6,18]}$}

a) Kalça eklemi distalinde kalan alt ekstremite yumuşak doku yaralanmalarında

b) Proksimal kruris kırıklarında

c) Distal femur kırıklarında

d) Patellar ve kuadriseps tendon yaralanmalarında

e) Nondeplase tibia şaft ve kapalı redükte edilebilen deplase tibia kırıklarında

\section{Silindir (Boru) Alçı (Şekil 4)}

Diz tam ekstansiyondayken, kruris ve uyluğu sirküler şekilde sararak tespit eden alçıdır. Bu alçı yürümeye olanak tanıyan bir alçı tipidir. Uzun bacak alçı yapımında dikkat edilmesi gereken hususlar bu alçı yöntemi için de geçerlidir ve yardımcı sağlık personeline ihtiyaç vardır. Farklı olarak, malleol kısmı bol pamukla ya da pedle desteklenmelidir. Aksi takdirde, hasta yürürken aşağı doğru sıyrılan alçı malleollerde bası yaparak ciddi yara açılmasına neden olabilir. Bu alçı, amacı diz fleksiyonuna engel olmak olduğu için, diz tam ekstansiyonda iken uygulanır. ${ }^{[2,6]}$ 


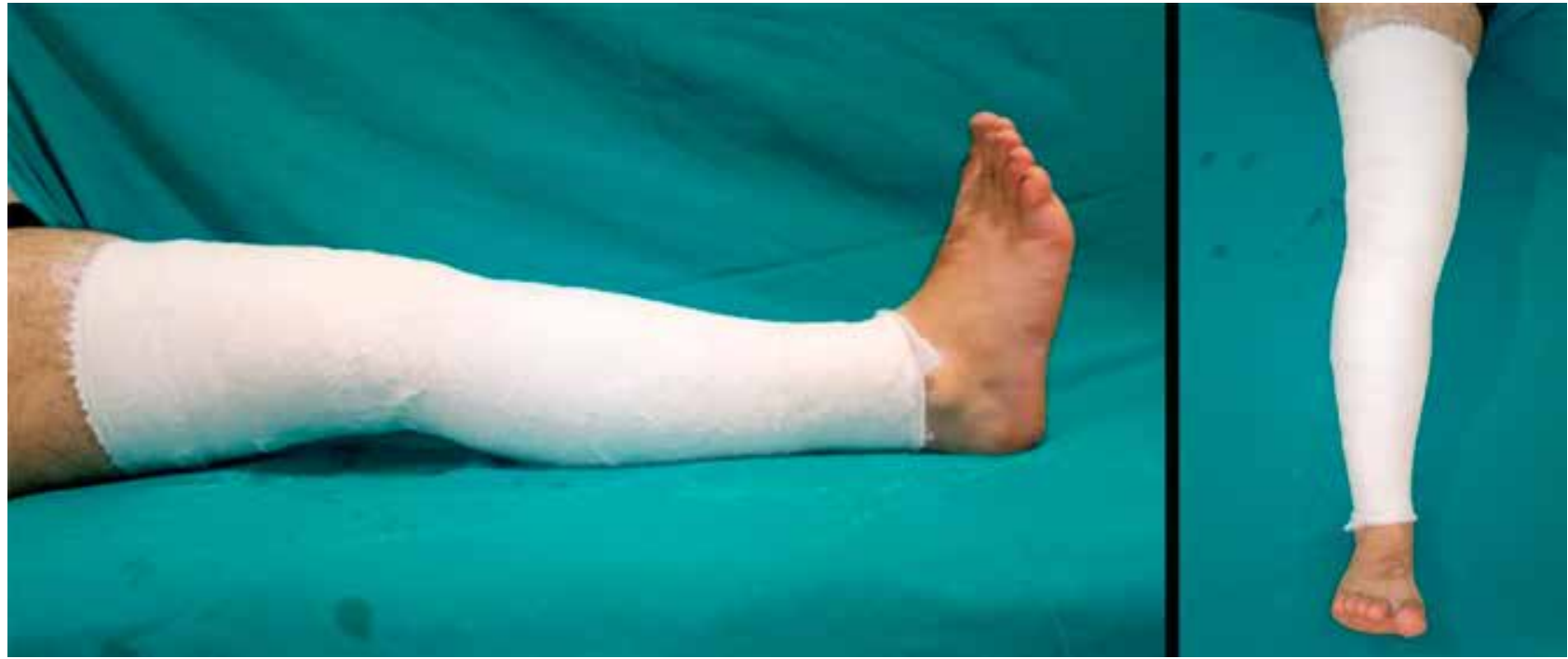

Şekil 4. Silindir (boru) alçı.

\section{Endikasyonlar ${ }^{[19,20]}$}

a) Diz çevresi yumuşak doku yaralanmaları

b) Patella kırığı

c) Patellar tendon ve kuadriseps tendon yaralanmalarında

\section{Pelvipedal Alçı}

Meme hizasının distalinden başlayıp ayak bileğine kadar tüm vücudu saran alçıdır. Dize ya da topuğa kadar uzatılabilmektedir. Sarma işlemine başlamadan önce, göbek bölgesine alçı altı pamuk ruloları yerleştirilerek abdominal bölgedeki bası ihtimali azaltılır. Abdominal dolaşımı takip etmek ve bası oluşmasına engel olmak için, alçı kuruduğunda bu bölgeye pencere açılabilir. ${ }^{[6,21]}$ Kalçalar $60-90^{\circ}$ fleksiyonda ve $30^{\circ}$ abduksiyonda, dizler $90^{\circ}$ fleksiyonda uygulanır. Femur kırıklarının konservatif tedavisinde ise popliteal fossadan traksiyon desteği sağlanabilir. ${ }^{[1]}$ Eklem bölgelerinde, gerek pamuk gerekse alçı sararken " 8 " şeklinde geçiş yapılmalıdır. Alçının kuruması uzun zaman alabilir. Bu süreçte alçının üzeri örtülmemelidir; hatta kurumayı hızlandırmak için saç kurutma makinesi kullanılabilir. Bu süreçte, hastayı taşırken alçı avuç içleri ile tutulmalıdır. ${ }^{[6,21]}$ Alçıya destek olmak ve hastayı taşımaya yardımcı olmak amacıyla, ekstremiteler arasına alçı ile sarılmış çıta yerleştirilebilir. Alçı üzerinde parmak izleri oluşur ise lokal bası oluşma ihtimali yüksektir. Hasta yakınının bu konularda mutlaka eğitilmesi ve bilgilendirilmesi gerekmektedir. Alçının perineal bölgesi mutlaka açılmalı ve alçı uçları streç naylonlarla korunmalıdır. Uzun süreli tedavilerde alçı hijyeni çok önemlidir. Ayrıca, çocuk hastalarda alçı içine yabancı cisim düşmemesi konusunda dikkatli olunmalıdır. Bu yabancı cisimler bası yarası oluşması açısından tehlikelidir. Çocuğun ailesi bu konuda da özellikle uyarılmalıdır. ${ }^{[6,21]}$

\section{Endikasyonlar [6,22,23]}

a) Kalça çıkığı (gelişimsel kaça displazisi)

b) Pediatrik femur kırı̆ı

c) Ameliyat sonrası kalça ve uyluk bölgesinin tespitinde

d) Ameliyat edilemeyeceğine karar verilen (ileri derecede ağır hastalığı olan, ameliyatı kesinlikle kaldıramayacak olan) erişkin femur ve kalça kırığı hastalarında

Sonuç olarak; alçı veya alçı ateller, günlük ortopedi pratiğinde oldukça sık kullanılan uygulamalardır. İyi uygulandığı takdirde başarılı sonuçlar elde etmek mümkündür; uygulama şekli prognoza, deplasmana ve angülasyona etki eder. İyi uygulanmadığı durumlarda komplikasyonları ciddidir ve gizlenemez. Basınç yaraları, kompartman sendromu ve alçı sendromu gibi komplikasyonlar akılda tutulmalıdır. Hasta konforu ve kırık uçlarının çevre dokulara zarar vermemesi açısından, alçı atel gerekliliktir. Sirküler alçı yapmak el alışkanlığı gerektirir, uygulayan kişinin imzasını taşır. Önlüğünde veya formasında alçı lekesi olmayan ortopedist olmaz ve her ortopedist için alçı yapmak sanattır. 


\section{KAYNAKLAR}

1. Başal Ö, Duran KÇ. Ortopedi ve Travmatoloji Polikliniğindeki Uygulama Pratikleri. İçinde: Orthopaedics and Sports Medicine Guide for Researchers. Ankara: Derman Tıbbi Yayıncılık; p.886-914. Crossref

2. Bucholz RW, Heckman JD, Court-Brown CM, Tornetta P 3rd, editors. Rockwood and Green's Fractures in Adults, Vol 1. Philadelphia, PA: Lippincott Williams \& Wilkins; 2010.

3. Smith GE. The most ancient splints. BMJ 1908;1(2465):7326. https://doi.org/10.1136/bmj.1.2465.732

4. Peltier LF. Fractures: a history and iconography of their treatment.USA, San Francisco: Norman Publishing; 1990.

5. Szostakowski B, Smitham P, Khan WS. Plaster of Paris -Short History of Casting and Injured Limb Immobilization. Open Orthop J 2017;11(1):291-6. Crossref

6. Ceylan $\mathrm{HH}$. Ortopedik Alçı ve Atel Uygulamaları. Ankara: Hipokrat Kitabevi; 2018.

7. Boyd AS, Benjamin HJ, Asplund C. Principles of casting and splinting. Am Fam Physician 2009;79(1):16-22.

8. Halanski M, Noonan KJ. Cast and splint immobilization: complications. J Am Acad Orthop Surg 2008;16(1):30-40. Crossref

9. Polat O, Güler i, Tek i, Öğüt H, Yıldız A. Ayak Bileği Lateral Ligament Yaralanmaları Tedavisi ve Klinik Deneyimlerimiz. Ankara Üniversitesi Tıp Fakültesi Mecmuası 2002;55(3): 205-10.

10. Işıklar ZU, Bilen FE. Kalkaneus kırıkları. TOTBID (Türk Ortopedi ve Travmatoloji Birliği Derneği) Dergisi 2006;5(1-2):44-52.

11. Möller M, Movin T, Granhed H, Lind K, Faxén E, Karlsson J. Acute rupture of tendo Achillis: a prospective, randomised study of comparison between surgical and non-surgical treatment. J Bone Joint Surg B 2001;83-B(6):843-8. Crossref
12. Sarmiento A. A functional below-the-knee cast for tibial fractures. J Bone Joint Surg Am 1967;49(5):855-75. Crossref

13. Sarmiento A. Functional bracing of tibial fractures. Clin Orthop Relat Res 1974;105(1):202-19. Crossref

14. Alimerzaloo F, Kashani RV, Saeedi H, Farzi M, Fallahian $\mathrm{N}$. Patellar tendon bearing brace: combined effect of heel clearance and ankle status on foot plantar pressure. Prosthet Orthot Int 2014;38(1):34-8. Crossref

15. Altındaş $M$, Çeber $M$, Bağhaki $S$. Total Temas Alçısı ile Diyabete Bağlı Nörotrofik Ayak Ülserlerinin Tedavisi: 44 Olguluk Seri. Turkiye Klinikleri J Med Sci 2011;31(4):882-9. Crossref

16. Myerson M, Papa J, Eaton K, Wilson K. The total-contact cast for management of neuropathic plantar ulceration of the foot. J Bone Joint Surg Am 1992;74(2):261-9. Crossref

17. Kılıçoğlu Ö. Diyabetik Ayak Biyomekaniği ve Yükten Kurtarma. Turkiye Klinikleri J Gen Surg-Special Topics 2010;3(1):65-74.

18. Drakos $\mathrm{MC}$, Murphy $\mathrm{Cl}$. Bracing versus casting in ankle fractures. Phys Sports Med 2014;42(4):60-70. Crossref

19. Larsen E, Lauridsen F. Conservative treatment of patellar dislocations. Influence of evident factors on the tendency to redislocation and the therapeutic result. Clin Orthop Relat Res 1982;(171):131-6. Crossref

20. de Palma AF. Fractures of Patella, The Management of Fractures and Dislocations, Vol. 2. Philadelphia, PA: WB Saunders Company;1959. p.706-29.

21. Bucholz RW, Heckman JD, Court-Brown CM, Tornetta P 3rd, editors. Rockwood and Wilkins' Fractures in Children, Vol 3. Philadelphia, PA: Lippincott Williams \& Wilkins; 2010.

22. Dameron TB Jr, Thompson HA. Femoral-Shaft Fractures in Children: Treatment by Closed Reduction and Double Spica Cast Immobilization. J Bone Joint Surg Am 1959;41(7):120112. Crossref

23. Aktaş Ş, Sarısaltık H. Çocuk femur cisim kırıklarında tedavi seçimi. Acta Ortop Traumatol Turc 1997;31:198-202. 